Interplay Between Ionization and Tautomerism in Bioactive $\beta$ Enamino Ester-Containing Cyclic Compounds: Study of Annulated

\title{
1,2,3,6-Tetrahydroazocine Derivatives
}

Antonio Viayna, ${ }^{\dagger}$ Salvatore G. Antermite, ${ }^{\ddagger}$ Modesto de Candia, ${ }^{\ddagger}$ Cosimo D. Altomare and F. Javier Luque ${ }^{+*}$

${ }^{\dagger}$ Department of Nutrition, Food Science and Gastronomy, Faculty of Pharmacy and Food Sciences, Institute of Biomedicine (IBUB) and Institute of Theoretical and Computational Chemistry (ITQCUB), University of Barcelona, Av. Prat de la Riba 171, E-08921 Santa Coloma de Gramenet, Spain

* Department of Pharmacy-Drug Sciences, University of Bari Aldo Moro, Via E. Orabona 4, I-70125 Bari, Italy 


\section{ABSTRACT}

Depending on the chemical scaffold, the bioactive species could reflect the interplay between ionization and tautomerism, often complicated by the possibility to populate different conformational states in the case of flexible ligands. In this context, theoretical methods can be valuable to discern the role of these factors, as shown here for $\beta$ enamino esters of 1,2,3,6-tetrahydroazocino fused ring systems, some of which had proven to be suitable scaffolds for designing novel acetylcholinesterase inhibitors. The compounds investigated herein form two clusters with distinctive experimental $\mathrm{p} K_{\mathrm{a}}$ values (i.e., $\alpha, \beta$-diesters and $\beta$-esters ranging within 6.1-7.3 and 8.2-9.0 $\mathrm{p} K_{\mathrm{a}}$ intervals, respectively), which implies a drastic difference in the most populated species at physiological conditions. While chemoinformatic tools did not provide a consistent description of the actual $\mathrm{p} K_{\mathrm{a}}$ values, the theoretical analysis performed for the protonated and neutral species of these compounds revealed a marked change in the tautomeric preference of the tetrahydroazocine moiety upon (de)protonation. Excellent agreement between calculated and experimental $\mathrm{p} K_{\mathrm{a}}$ values was found when the tautomeric preference of protonated and neutral species was considered. Overall, this study highlights the potential use of high-level computational methods to disclose the mutual influence between ionization, tautomerism and conformational preferences in multifunctional (bio)organic compounds. 


\section{INTRODUCTION}

Finding the bioactive species that mediates the functional role of small molecules is crucial to gain insight into many biochemical processes of the cell. ${ }^{1}$ This knowledge permits to disclose the molecular determinants implicated in the recognition and binding of the ligand to specific macromolecular targets, hence providing a basis to understand the mechanism of action of small (bio)organic compounds. Furthermore, it may be valuable for disclosing the relationships between chemical structure and biological activity, highlighting clues for the design of novel compounds with improved functional profile.

The identification of the bioactive species may often be challenging, especially for ionizable small molecules, as the chemical features of a given compound can modulate the balance between distinct ionization and tautomeric states. ${ }^{2-9}$ Moreover, depending upon the number of rotatable bonds in the chemical skeleton of the compound, the ionization and tautomeric preferences may influence the population of distinct conformational wells, reflecting the balance between intramolecular interactions, such as hydrogen bonds or stacking interactions, and intermolecular interactions (i.e., with solvent molecules and co-solutes present in condensed media). ${ }^{10-13}$ This scenario may be further complicated by the presence of stereocenters in the chemical structure of the compound. Overall, the activity of the compound is dictated by the interplay between ionization, tautomerism and conformational flexibility. On the other hand, these chemical features will also modulate the physicochemical behavior of the compound, affecting properties such as solubility, partitioning in aqueous/organic phases and biodistribution in the organism. ${ }^{14,15}$

Dissecting the interplay between the aforementioned factors may be important for better characterizing the physicochemical and biological profile of a compound. This could be 
illustrated by a series of $\beta$-enamino ester derivatives of annulated (e.g., $1 H$-pyrrole-, $1 H$-indole- and pyrimidine-fused) 1,2,3,6-tetrahydroazocines, which were previously synthesized and assayed by some of us as acetylcholinesterase inhibitors with potential application for the treatment of mild Alzheimer's disease. ${ }^{16,17}$ The main structural variations affecting acid-base equilibria of the $\beta$-enamino ester-containing heterocyclic compounds are exemplified for the two $1 H$-indole-fused tetrahydroazocine scaffolds shown in Table 1, namely the fusion isomers 2,3,6,11-tetrahydro- $1 H$-azocino[4,5$b$ ]indole (set I) and 2,3,6,7-tetrahydro- $1 H$-azocino[5,4-b]indole (set II). Within each molecular set, major variations pertain to the presence of a second ester group $\left(R_{2}=H\right.$ or $\mathrm{COOMe}) \alpha$ to the enamino $\mathrm{N}$ and the size-increasing alkyl groups at $\mathrm{C}_{6}$ in set $\mathbf{I I}\left(\mathrm{R}_{4}\right.$ $=\mathrm{Me}, i \mathrm{Pr}, \mathrm{Bn}$ ), whereas the differences in the alkyl groups in $\mathrm{R}_{1}$ and $\mathrm{R}_{3}$ appear to not significantly affect the basicity of N3.

Table 1. General structures, numbering and experimental $\mathrm{p} K_{\mathrm{a}}$ of the investigated $\beta$-enamino ester derivatives of (I) 2,3,6,11-tetrahydro-1 $H$-azocino[4,5-b]indole and (II) 2,3,6,7-tetrahydro$1 H$-azocino[5,4-b]indole. The $\beta$-enamino ester function is colored in blue.

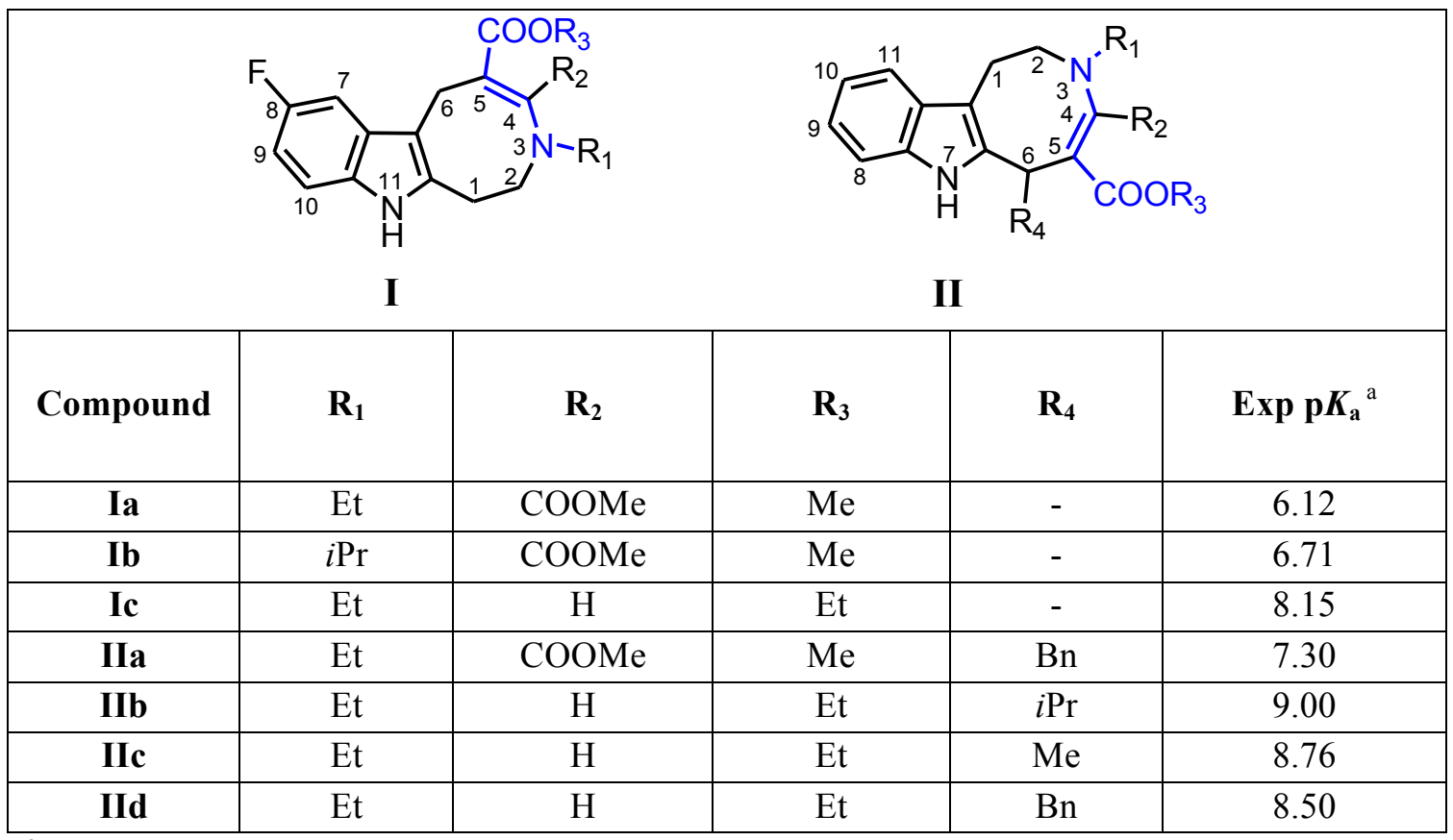

${ }^{\mathrm{a}}$ Values taken from ref. 17 
The biological properties of these compounds, including ADMET (Absorption, Distribution, Metabolism, Excretion and Toxicity) profiles, could be affected by the susceptibility of the nitrogen atom to be protonated. This may depend on the $\mathrm{COOR}_{3}$ substituents $\alpha$ or $\beta$ to the enamino $\mathrm{N}$ and on the conformational flexibility of the fused tetrahydroazocine ring, which in turn may differ in the scaffold chemotypes I and II. As a matter of fact, the enamino esters investigated herein form two clusters of experimental $\mathrm{p} K_{\mathrm{a}}$ values, namely $\alpha, \beta$-diesters (Ia, Ib and IIa), with values ranging within 6.1-7.3, and $\beta$-esters (Ic, IIb, IIc and IId) ranging within 8.1-9.0 (Table 1). Remarkably, this implies that the predominant species in aqueous solution at physiological $\mathrm{pH}$ will be neutral or protonated, respectively, which is relevant not only for identifying the bioactive species, but also affects the feasibility to cross biological barriers, such as the blood-brain barrier for compounds acting at the central nervous system.

In this context, this study aims to examine the interplay between ionization, tautomerism and conformational preferences, in order to interpret the behavior of the enamino ester derivatives of $1 H$-indole-fused tetrahydroazocines. At this point, it can be hypothesized that the stability of the enamine species may be altered upon protonation, favoring the transition to alternative tautomeric species where the double bond between $\mathrm{C}_{4}$ and $\mathrm{C}_{5}$ is shifted to $\mathrm{C}_{5}$ and $\mathrm{C}_{6}$ (Scheme 1). This process will switch the electron delocalization of the double bond with the azocino nitrogen N3 by the conjugation with the $\pi$-electron density of the indole ring. Moreover, the description of this process may be influenced by the changes in conformational flexibility arising from the different skeleton of the azocino ring in the two tautomers, and by the substituents attached to the ring. Accordingly, this study reports the results of high-level ab initio quantum mechanical $(\mathrm{QM})$ calculations performed to examine the mutual influence between 
ionization and tautomerism, in conjunction with the Multilevel methodology, ${ }^{11,13}$ to carry out the conformational sampling of the compounds. The results highlight the subtle influence of these factors on the bioactive species of these compounds.

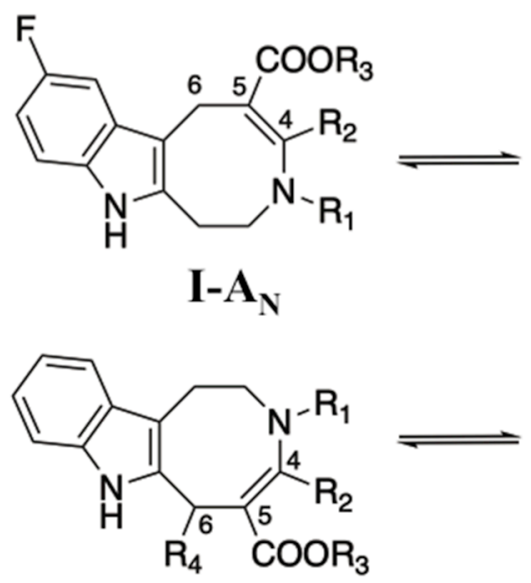

II-A

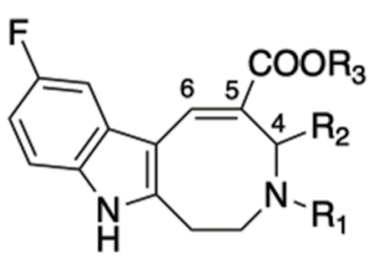

${\mathbf{I}-\mathbf{B}_{\mathrm{N}}}$

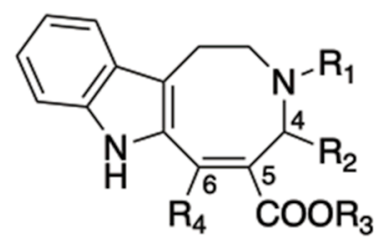

II-B $_{\mathrm{N}}$

Scheme 1. Representation of the tautomeric equilibria in the two sets of $\beta$-enamino esters of $1 H$-indole-fused tetrahydroazocines.

\section{METHODS}

Molecular systems. The theoretical study was performed for the generic compounds I $\left(\mathrm{R}_{1}=\mathrm{Me} ; \mathrm{R}_{2}=\right.$ COOMe; $\left.\mathrm{R}_{3}=\mathrm{Me}\right)$ and II $\left(\mathrm{R}_{1}=\mathrm{Me} ; \mathrm{R}_{2}=\mathrm{H} ; \mathrm{R}_{3}=\mathrm{R}_{4}=\mathrm{Me}\right)$ shown in Scheme 1, which are strictly related to Ia and IIc, respectively (Table 1). Compared to Ia, compound I differs by the replacement of the ethyl group $\left(\mathrm{R}_{1}\right)$ with methyl in N3. Besides the $\mathrm{Et} \rightarrow \mathrm{Me}$ replacement, the COOEt at $\mathrm{C} 5$ in IIc was replaced by COOMe in II. While these changes simplify the conformational space of the molecules, and reduce the expensiveness of computations, they are not expected to have a significant influence on the $\mathrm{p} K_{\mathrm{a}}$ of compounds Ia and IIc, which was determined to be $6.12( \pm 0.04)$ and 8.76 $( \pm 0.12)$, respectively (values in parentheses represent standard deviations of the mean $\mathrm{p} K_{\mathrm{a}} \mathrm{s}$, as obtained from the fitting to potentiometric curves of at least three independent determinations). Finally, the choice of these compounds was also motivated by the 
structural information available for the same (Ia) or related (IIb) compounds in the Cambridge Crystallographic Data Centre (CCDC code 218170 and 229769, respectively; Figure 1). ${ }^{18}$ Note that the CCDC structures correspond to the neutral tautomers $\mathbf{I}-\mathbf{A}_{\mathbf{N}}$ for $\mathbf{I a}$, and $\mathbf{I I}-\mathbf{B}_{\mathbf{N}}$ for $\mathbf{I I b}$, respectively.
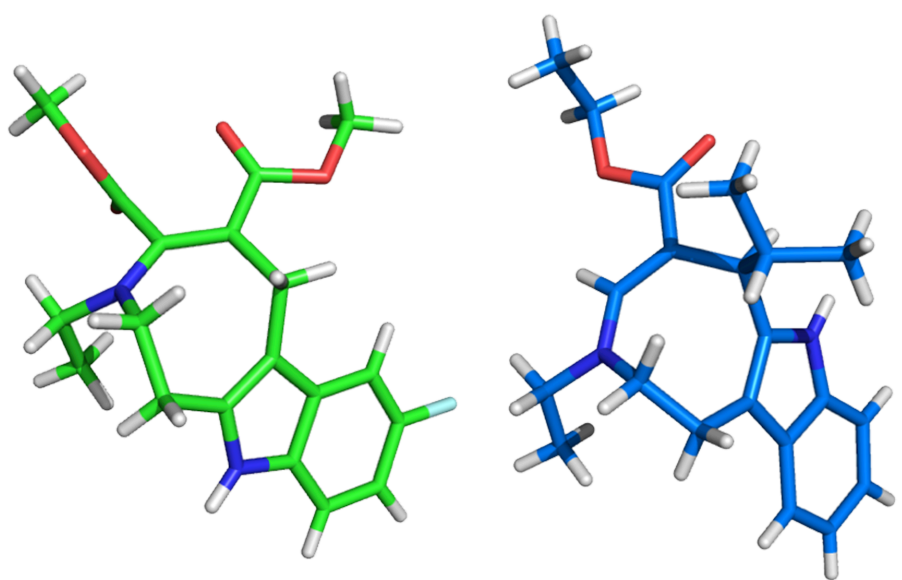

Figure 1. Crystallographic structures of the enamino species of neutral compounds (left) Ia (CCDC code: 218170) and (right) IIb (CCDC code: 229769).

$\mathbf{p} \boldsymbol{K}_{\mathbf{a}}$ estimation. The calculation of $\mathrm{p} K_{\mathrm{a}}$ generally relies on the use of the thermodynamic cycle shown in Figure 2. According to this cycle, the free energy change for the deprotonation of the acidic species $\left(A_{P}\right)$ to give the neutral form $\left(A_{N}\right)$ in aqueous solution $\left(\Delta G_{a q}\right.$ ) can be related to the free energy difference between reactants and products in the gas phase ( $\Delta G_{g a s}$; Eq. 1), and the change in the hydration free energy of the protonated species $\left(\Delta G_{s o l}\left(\mathrm{~A}_{\mathrm{P}}\right)\right)$ relative to the neutral form $\left(\Delta G_{s o l}\left(\mathrm{~A}_{\mathrm{N}}\right)\right)$ and the proton $\left(\Delta G_{s o l}\left(\mathrm{H}^{+}\right) ;\right.$Eq. 2$)$.

$$
\begin{aligned}
& \Delta G_{g a s}=G_{g a s}\left(\mathrm{H}^{+}\right)+G_{g a s}\left(\mathrm{~A}_{\mathrm{N}}\right)-G_{g a s}\left(\mathrm{~A}_{\mathrm{P}}\right) \\
& \Delta G_{a q}=\Delta G_{g a s}+\Delta G_{s o l}\left(\mathrm{H}^{+}\right)+\Delta G_{s o l}\left(\mathrm{~A}_{\mathrm{N}}\right)-\Delta G_{s o l}\left(\mathrm{~A}_{\mathrm{P}}\right)
\end{aligned}
$$




$$
\begin{aligned}
& \mathrm{A}_{\mathrm{P} \text { (gas) }} \stackrel{\Delta \mathrm{G}_{\text {gas }}}{\longrightarrow} \mathrm{H}^{+}{ }_{\text {(gas) }}+\mathrm{A}_{\mathrm{N} \text { (gas) }} \\
& -\Delta \mathrm{G}_{\mathrm{sol}}\left(\mathrm{A}_{\mathrm{P}}\right) \uparrow \quad \Delta \mathrm{G}_{\mathrm{sol}}\left(\mathrm{H}^{+}\right) \downarrow \Delta \mathrm{G}_{\mathrm{sol}}\left(\mathrm{A}_{\mathrm{N}}\right) \downarrow \\
& \mathrm{A}_{\mathrm{P}(\mathrm{aq})} \longrightarrow \mathrm{H}_{(\mathrm{aq})}^{+}+\mathrm{A}_{\mathrm{N}(\mathrm{aq})}
\end{aligned}
$$

Figure 2. Thermodynamic cycle used for the calculation of the $\mathrm{p} K_{\mathrm{a}}$ values of tetrahydroazocino ester derivatives.

Finally, the $\mathrm{p} K_{\mathrm{a}}$ of the compound was determined using the standard relationship shown in Eq. 3.

$$
\mathrm{p} K_{a}=\frac{\Delta G_{a q}}{R T \ln (10)}
$$

In this computational framework, the free energies of the protonated and neutral species were determined from the ensemble of conformations sampled by using the Multilevel strategy (see below). The free energy in aqueous solution of the proton was estimated by combining the experimental data of $G_{g a s}\left(\mathrm{H}^{+}\right)$and $\Delta G_{\text {sol }}\left(\mathrm{H}^{+}\right)$, which are -6.28 $\mathrm{kcal} / \mathrm{mol}$ and $-265.9 \mathrm{kcal} / \mathrm{mol}^{19,20} \mathrm{~A}$ correction term of $+1.89 \mathrm{kcal} / \mathrm{mol}$ was also introduced to account for the change in the reference states, which correspond to $1 \mathrm{~atm}$ and $24.46 \mathrm{~L}$ in the gas phase and $1 \mathrm{M}$ in aqueous solution at $298.15 \mathrm{~K}$.

Multilevel conformational sampling. To explore the conformational space of the protonated $\left(\mathrm{A}_{\mathrm{P}}, \mathrm{B}_{\mathrm{P}}\right)$ and neutral $\left(\mathrm{A}_{\mathrm{N}}, \mathrm{B}_{\mathrm{N}}\right)$ tautomers of compounds I and II (Scheme 1$)$, we adopted the computational strategy outlined in Figure 3. 
For each tautomeric species, five distinct conformers were generated with the Avogadro software $^{21}$ as starting structures to perform the conformational sampling with the Multilevel (ML) strategy. In the case of tautomer $\mathbf{A}$, one of these structures was taken from the CCDC crystallographic data (see Figure 1). The ML strategy relies on the use of two computational levels to determine the conformational preferences of flexible compounds: a low-level (LL) method is chosen to perform an exhaustive conformational search, and a high-level (HL) technique is subsequently used to determine the relative stability of the conformational wells In this work, the LL method involved the use of classical molecular dynamics performed with AMBER $16,{ }^{22}$ and the HL refinement was performed at the MP2 level with Gaussian16. ${ }^{23}$

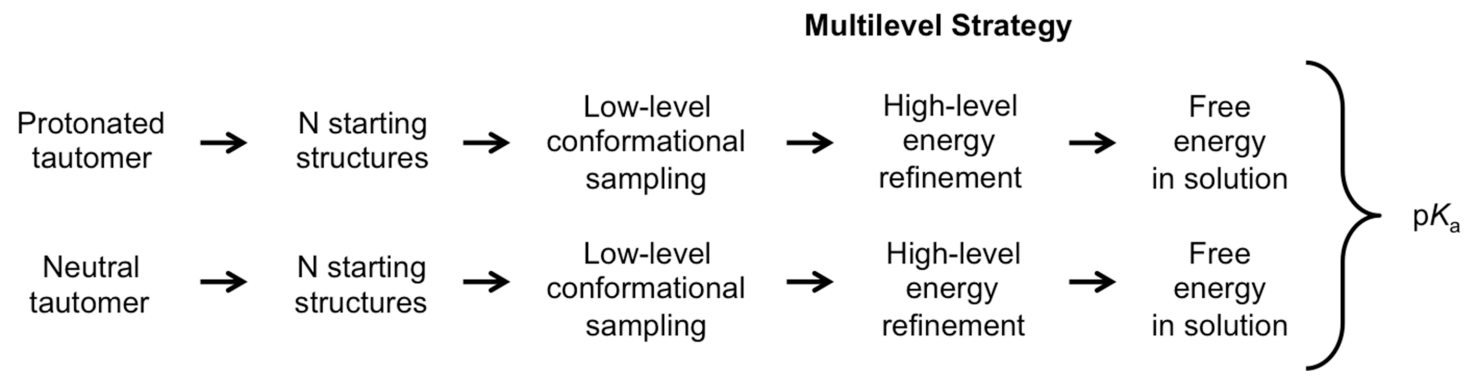

Figure 3. Computational scheme adopted for the conformational sampling of the protonated and neutral tautomers of the tetrahydroazocino ester derivates.

According to the predominant-states approximation adopted by Gilson and coworkers, ${ }^{24,25}$ the ML strategy partitions the conformational space sampled at the LL into $\mathrm{M}$ local energy wells, and the free energy $(A)$ is approximated from the freeenergy contributions $\left(A_{m}\right)$ of these wells (Eq 4).

$$
A \approx-R T \ln \sum_{i=1}^{M} e^{-A_{m} / R T}
$$


For a given well $m$, the free energy is expressed by combining the contribution of the minimum energy conformer $\left(E_{m_{-} \text {min }}\right)$ within the well, and the contribution due to the rest of conformers ( $\Delta A_{m}^{\text {local }}$ ) that populate the conformational family (Eq. 5; the reader is addressed to ref. 24 for a detailed derivation of this expression).

$$
A_{m}=E_{m_{-} \min }+\Delta A_{m}^{l o c a l}-R T \ln \frac{v_{m}}{N_{m}}
$$

where $v_{m}$ is the volume of configurational space for the conformational well $m, N_{m}$ stands for the number of conformational states in the well, and the contribution due to the local curvature, which reflects the width of the potential energy surface around the minimum energy conformer of the well, is given as

$$
\Delta A_{m}^{\text {local }}=-R T \ln \sum_{j=1}^{N_{m}} e^{-\Delta E_{j} / R T}
$$

where $\Delta E_{j} \approx E_{j}-E_{m_{-} \min }$.

Let us note that if one assumes a uniform sampling of the conformational volume associated to distinct wells $m$ and $n$, the contribution due to the last term in Eq. 5 will cancel, and the relative stability between two conformational families will be determined by the difference between the energy of the minimum-energy conformers and the local curvature of the wells.

Computational details. In this work, the LL sampling was performed via classical simulations of the tetrahydroazocino compounds immersed in a box (with edges located at $12 \AA$ from the ligand) of TIP3P water $^{26}$ molecules. The parametrization of the 
annulated tetrahydroazocines was made using the gaff force field, ${ }^{27}$ and the atomic point charges were determined using the $\operatorname{RESP}^{28}$ procedure by fitting the HF/6-31G(d) electrostatic potential. A chloride anion was added to the simulation systems corresponding to protonated compounds. After energy minimization, the temperature of the system was raised from 50 to $298 \mathrm{~K}$ in $200 \mathrm{ps}$ at constant volume, and the density of the system was equilibrated in a subsequent 200 ps run at constant temperature $(298 \mathrm{~K})$ and pressure (1 bar). Production runs at constant volume and temperature were performed using $\mathrm{SHAKE}^{29}$ for bonds involving hydrogen atoms, an integration time step of 1 fs, and periodic boundary conditions in conjunction with Particle Mesh Ewald $^{30}$ for the treatment of long-range electrostatic interactions, and a cutoff of $9 \AA$ for nonbonded interactions.

The HL refinement involved the geometry optimization of the minimum energy conformer for each conformational well using the IEF/MST ${ }^{31,32}$ continuum model parametrized at the $\mathrm{B} 3 \mathrm{LYP} / 6-31 \mathrm{G}(\mathrm{d})$. The minimum energy nature was confirmed by analysis of the vibrational frequencies. Following our previous implementation, ${ }^{11,13}$ a single-point calculation at the MP2/aug-cc-pVDZ level was carried out to refine the energy of the optimized structure $\left(E_{m_{-} \min }^{M P 2}\right)$. The final estimate of the conformational free energy was evaluated by adding the zero-point energy correction $\left(Z P E_{m}^{I E F / M S T}\right.$ ) and the hydration free energy ( $\Delta A_{s o l, m}^{I E F / M S T}$ ), both calculated at the IEF-MST/B3LYP/631G(d) level (Eq. 7).

$$
E_{m_{-} \min }=E_{m_{-} \min }^{M P 2}+Z P E_{m}^{I E F / M S T}+\Delta A_{h y d, m}^{I E F / M S T}
$$


The application of this procedure to the set of structures that define the curvature of the well would be computationally cumbersome. Therefore, its contribution was estimated from the LL sampling by projecting the conformers onto a $k$-dimensional grid, with $k$ being the number of active torsions associated to the flexibility of the azocino ring and attached substituents. For each grid element $j$, an effective energy was estimated from the conformer population, and the local curvature contribution was determined from the ratio (Eq. 8) between the population of sampled structures assigned to grid element $j$ ( $\left.\rho_{j}\right)$ and the grid point with the largest population $\left(\rho_{m_{-} \min }\right)$.

$$
\Delta A_{m}^{\text {local }}=-R T \ln \sum_{j=1}^{N_{m}} \frac{\rho_{j}}{\rho_{m_{-} \min }}
$$

Experimental determination of $\mathbf{p} \boldsymbol{K}_{\mathrm{a}}$. Ionization constants $\left(\mathrm{p} K_{\mathrm{a}}\right)$ were determined through potentiometric titration using a Sirius GLpKa instrument (Sirius Analytical Instruments Ltd.). All the experiments were carried out in triplicate at $25 \pm 0.5{ }^{\circ} \mathrm{C}$, under a slow argon flow, to avoid $\mathrm{CO}_{2}$ interferences, and data were finally processed using the RefinementPro ${ }^{\mathrm{TM}}$ software (Sirius Analytical Instruments Ltd.). Details about instrument and procedures are reported elsewhere. ${ }^{17,33-35}$

A right amount of each compound was dissolved in $20 \mathrm{~mL}$ of $0.15 \mathrm{M} \mathrm{KCl}$ solution containing methanol $(15 \%$ to $45 \%, \mathrm{v} / \mathrm{v})$ as the cosolvent, to achieve a final sample concentration of about $0.5 \mathrm{mM}$. The test solutions were titrated, under argon flow, using standardized $0.5 \mathrm{M} \mathrm{HCl}$ and $0.5 \mathrm{M}$ carbonate free $\mathrm{KOH}$ solutions as titrating agents and the data recorded in the $\mathrm{pH}$ range between 1.8 and 12 . The maximum volume increments of titrant solutions were $0.25 \mathrm{~mL}$. The $\mathrm{pH}$ changes after addition of titrant volume were limited to $0.2 \mathrm{pH}$ units; the $\mathrm{pH}$ value in each point was collected when the $\mathrm{pH}$ drift was lower than $0.002 \mathrm{pH} / \mathrm{min}$. Before starting experimental session, the 
instrument underwent daily the glass electrode standardization, based on a fourparameter equation and a weighted nonlinear least squares procedure. ${ }^{36}$

Each titration was performed at least in triplicate and the derived Bjerrum plots, obtained by applying the four-parameter equation for glass electrode calibration, were used to calculate precise apparent $\mathrm{p} K_{\mathrm{a}}$ values. Finally, based on the Yasuda-Shedlovsky equation implemented in RefinementPro ${ }^{\mathrm{TM}}$ software, ${ }^{37,38} \mathrm{p} K_{\mathrm{a}}$ at $100 \%$ aqueous solution was obtained by extrapolation. ${ }^{39}$

\section{RESULTS AND DISCUSSION}

A remarkable difference in the experimental $\mathrm{p} K_{\mathrm{a}}$ values of the cyclic enamine derivatives investigated herein, with $\mathrm{p} K_{\mathrm{a}}$ values ranging from 6.1 to 7.3 (median 6.7) for $\alpha, \beta$-diester derivatives, and from 8.1 to 9.0 (median 8.6) for $\beta$-ester derivatives, is observed irrespective of the fusion isomerism of the $1 H$-indole-fused tetrahydroazocine scaffolds I and II (Table 1). Even considering the involvement of the tautomeric equilibrium shown in Scheme 1, a consistent description of the differences in $\mathrm{p} K_{\mathrm{a}}$ values cannot be gained from chemoinformatic tools. When the $\mathrm{p} K_{\mathrm{a}}$ of these compounds was estimated with MarvinSketch ${ }^{\circledR}$ software, $^{40}$ the results predicted for the amino species (tautomer B) were similar to the experimental values, whereas the $\mathrm{p} K_{\mathrm{a}}$ of the enamino species (tautomer A) differed by more than $8 \mathrm{p} K_{\mathrm{a}}$ units (Table 2). However, the results obtained using ACDLabs ${ }^{41}$ showed a slight sensitivity to the tautomeric species, as the $\mathrm{p} K_{\mathrm{a}}$ values determined for tautomers $\mathbf{A}$ and $\mathbf{B}$ differed by less than $1 \mathrm{p} K_{\mathrm{a}}$ unit (Table 2). These differences are surprising, as several studies have reported that these methods exhibit a close agreement in the $\mathrm{p} K_{\mathrm{a}}$ prediction of ionizable sites for a variety of compounds, leading to $\mathrm{p} K_{\mathrm{a}}$ estimates that accurately reproduce the experimental values (generally with mean average deviations $<0.7$ log units). ${ }^{42-45}$ However, these studies 
have often found discrepancies in the predicted $\mathrm{p} K_{\mathrm{a}}$ values that appear to be related to the presence of specific chemical features, ${ }^{45}$ which likely originate from the different nature of the formalisms used by these tools in the $\mathrm{p} K_{\mathrm{a}}$ prediction and the chemical diversity and structural complexity of the compounds included in the datasets. Overall, these data pose the question about the origin of the chemical factors that determine the experimental $\mathrm{p} K_{\mathrm{a}}$ of the two sets of tetrahydroazocino enamino ester derivatives. Here to follow, we examine separately the interplay between ionization and tautomerism and its impact on the bioactive species of $\alpha, \beta$-diester and $\beta$-ester of the fused heterocyclic scaffolds I and II, respectively.

Table 2. Experimental and Calculated $\mathrm{p} K_{\mathrm{a}}$ Values for Representative Members of The Two Sets of $\beta$-Enamino Esters of $1 H$-Indole-Fused Tetrahydroazocines.

\begin{tabular}{|c|c|c|c|c|c|}
\hline \multirow{2}{*}{ Compound } & \multirow{2}{*}{$\operatorname{Exp~p}_{\mathbf{a}}$} & \multicolumn{4}{|c|}{${\text { Calc } \mathbf{~} \boldsymbol{K}_{\mathbf{a}}}$} \\
\cline { 3 - 6 } & & \multicolumn{2}{|c|}{$\mathbf{M S}^{\mathbf{a}}$} & \multicolumn{2}{|c|}{ ACDLabs $^{\mathbf{b}}$} \\
\cline { 3 - 6 } & & $\mathrm{A}_{\mathrm{N}}$ & $\mathrm{B}_{\mathrm{N}}$ & $\mathrm{A}_{\mathrm{N}}$ & $\mathrm{B}_{\mathrm{N}}$ \\
\hline Ia & 6.12 & -5.68 & 5.33 & 4.85 & 5.47 \\
\hline Ib & 6.71 & -5.41 & 5.58 & 5.09 & 5.55 \\
\hline Ic & 8.15 & -1.09 & 7.41 & 6.84 & 7.46 \\
\hline IIa & 7.30 & -5.30 & 5.73 & 5.35 & 5.87 \\
\hline IIb & 9.00 & -0.64 & 7.91 & 7.32 & 7.84 \\
\hline IIc & 8.76 & -0.75 & 7.79 & 7.36 & 7.88 \\
\hline IId & 8.50 & -0.73 & 7.80 & 7.34 & 7.86 \\
\hline
\end{tabular}

${ }^{a}$ Values calculated using MarvinSketch system (version 17.29.0). ${ }^{b}$ Values calculated using ACDLabs suite (version 2014.1).

Prediction of $\mathbf{p} K_{\mathrm{a}}$ in the Multilevel framework. Before undertaking this study, the chemical accuracy of the HL method used in the ML strategy for predicting the $\mathrm{p} K_{\mathrm{a}}$ was checked for a series of nitrogen-containing heterocyclic compounds (Table 3 ). The $\mathrm{p} K_{\mathrm{a}}$ 
was estimated from Eqs. 1-3, taking advantage of the lack of relevant conformational effects in these compounds.

To this end, the geometries of protonated and neutral species were optimized with the IEF/MST solvation model at the B3LYP/6-31G(d) level. Then, single-point MP2/augcc-pVDZ energy calculations were performed to obtain the $\Delta G_{g a s}$ component, which was corrected by adding the ZPE contribution, and the relative hydration free energy of protonated and neutral species determined from continuum calculations. For the sake of comparison, similar calculations were performed at the $\operatorname{CCSD}(\mathrm{T})$ level using the augcc-pVDZ basis set in order to take into account higher-order correlation effects in the calculation of $\Delta G_{\text {gas }}$. These levels of theory are denoted ML(MP2) and ML(CCSD(T)) in Table 3.

There is a nice agreement between experimental and predicted results. The calculated $\mathrm{p} K_{\mathrm{a}}$ values tend to be, on average, around $0.5 \mathrm{p} K_{\mathrm{a}}$ units lower/higher than the experimental ones at the ML(MP2) and $\operatorname{ML}(\operatorname{CCSD}(\mathrm{T}))$ levels, respectively, although this is mainly due to the deviation in the predicted value of pyridine at the ML(MP2) level, and to morpholine in the $\operatorname{ML}(\operatorname{CCSD}(\mathrm{T}))$ case. Nevertheless, the two methods lead to a similar root-mean square deviation (RMSD), which amounts to $c a .1 \mathrm{p} K_{\mathrm{a}}$ unit. Remarkably, the similar accuracy attained from these computations is achieved at a much lower cost at the ML(MP2) level. Overall, this analysis supports the suitability of the QM level of theory implemented in the ML strategy for the computation of $\mathrm{p} K_{\mathrm{a}}$ in the series of tetrahydroazocino ester derivatives.

Table 3. Experimental and Calculated $\mathrm{p} K_{\mathrm{a}}$ Values Determined for a Series of NitrogenContaining Heterocycles.

\begin{tabular}{|c|c|c|c|c|c|}
\hline Compound & Expt. & ML(MP2) & ML(CCSD(T)) & MS $^{\text {a }}$ & ACDLabs $^{\mathbf{b}}$ \\
& $\mathrm{p} K_{\mathrm{a}}$ & $\mathrm{p} K_{\mathrm{a}}$ & $\mathrm{p} K_{\mathrm{a}}$ & $\mathrm{p} K_{\mathrm{a}}$ & $\mathrm{p} K_{\mathrm{a}}$ \\
\hline
\end{tabular}




\begin{tabular}{|l|c|c|c|c|c|}
\hline Pyridine & 5.2 & 3.3 & 5.1 & 5.1 & 5.2 \\
\hline Quinoline & 4.9 & 3.6 & 3.9 & 4.5 & 5.0 \\
\hline Tetrahydroquinoline & 5.0 & 4.3 & 5.4 & 4.9 & 5.1 \\
\hline Imidazole & 6.9 & 6.4 & 6.9 & 7.0 & 7.2 \\
\hline Morpholine & 8.5 & 9.6 & 10.7 & 8.5 & 9.0 \\
\hline Tacrine & 9.9 & 9.8 & 9.6 & 9.0 & 9.6 \\
\hline Piperidine & 11.3 & 11.3 & 12.6 & 10.4 & 10.4 \\
\hline Mean signed error & & -0.5 & 0.4 & 0.3 & 0.2 \\
\hline RMSD & & 1.0 & 1.1 & 0.5 & 0.4 \\
\hline
\end{tabular}

${ }^{\mathrm{a}}$ Calculated with MarvinSketch (version 17.29.0). ${ }^{\mathrm{b}}$ Calculated with ACDLabs (version 2014.1).

Multilevel analysis of compound I. The ionization and tautomeric equilibria of this compound gives rise to four chemical entities (Figure 4), where $\mathbf{A}_{\mathbf{P}}$ and $\mathbf{B}_{\mathbf{P}}$ stand for the protonated species of the two tautomers, and the corresponding neutral forms originated upon deprotonation are denoted $\mathbf{A}_{\mathbf{N}}$ and $\mathbf{B}_{\mathbf{N}}$, respectively.

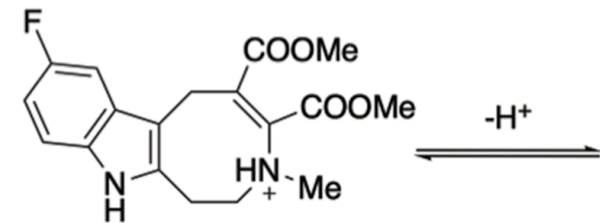<smiles>COC(=O)C1=C(C(C)=O)N(C)CCc2[nH]c3ccc(F)cc3c2C1</smiles>
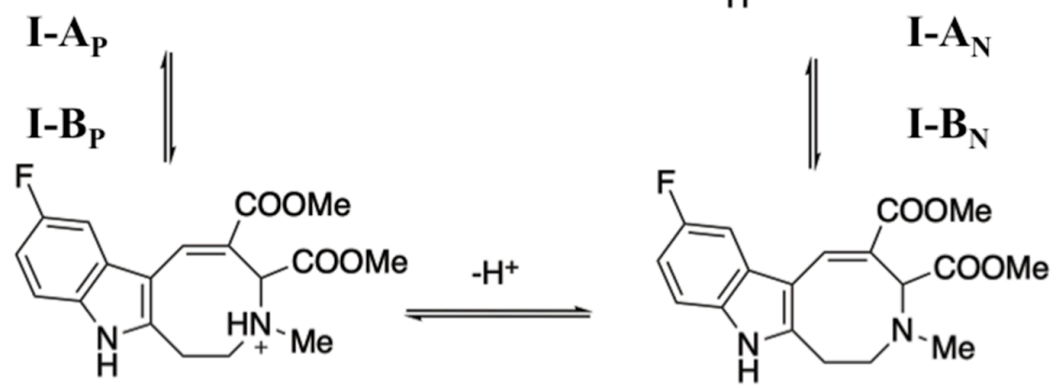

Figure 4. Representation of the ionization equilibria and tautomerism for protonated $\left(\mathbf{A}_{\mathbf{P}}, \mathbf{B}_{\mathbf{P}}\right)$ and neutral $\left(\mathbf{A}_{\mathbf{N}}, \mathbf{B}_{\mathbf{N}}\right)$ species of compound $\mathbf{I}$.

The conformational sampling performed for $\mathbf{I}-\mathbf{A}_{\mathbf{P}}$ and $\mathbf{I}-\mathbf{A}_{\mathbf{N}}$ reveals the preference for structures characterized by a folded conformation of the azocino ring (Figure 5). The 
folded arrangement is more pronounced in the protonated structure, I- $\mathbf{A}_{\mathbf{P}}$, as it favors the electrostatic interaction between the positive charge of the protonated amine and the $\pi$-electron cloud of the indole ring. The conformational flexibility primarily reflects the orientations adopted by the ester groups, leading to two main conformational states corresponding to $71.4 \%\left(\mathbf{A}_{\mathbf{P}}{ }^{1}\right)$ and $27.4 \%\left(\mathbf{A}_{\mathbf{P}}{ }^{2}\right)$ respectively, for the protonated structure (Figure 5 and Supporting Information Figure S1), and four conformers for the neutral one, with a population ranging from $55.6 \%$ to $10.2 \%$ (Figure 5 and Supporting Information Figure S2).

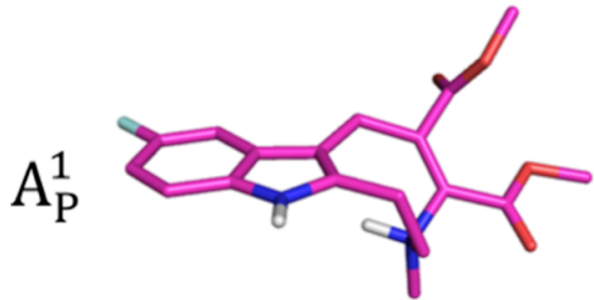

$(71.4 \%)$

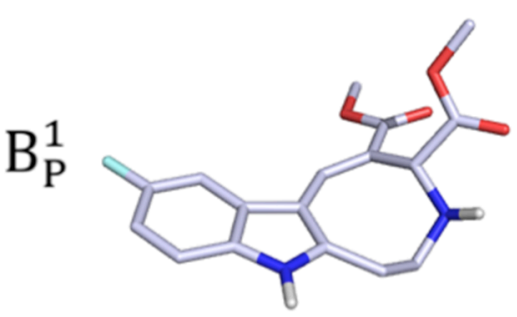

$(63.6 \%)$

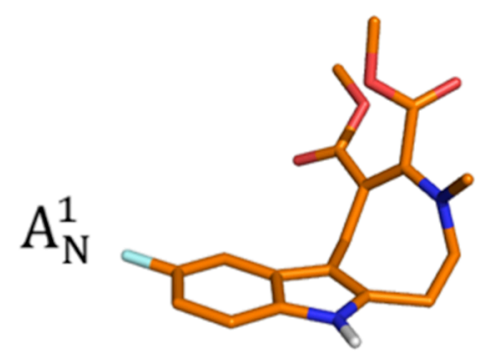

$(55.6 \%)$

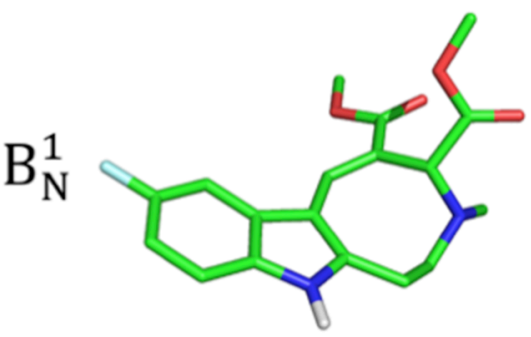

$(62.2 \%)$

Figure 5. Main conformers in solution for the protonated $\left(\mathbf{A}_{\mathbf{P}}{ }^{1}, \mathbf{B}_{\mathbf{P}}{ }^{1}\right)$ and neutral $\left(\mathbf{A}_{\mathbf{N}}{ }^{1}, \mathbf{B}_{\mathbf{N}}{ }^{1}\right)$ tautomeric species of compound I determined from the ML sampling. The population (\%) of the main symmetry-related conformation for each species is shown in parenthesis.

It is worth noting that the conformation of the tricyclic ring is highly similar in the four conformers of $\mathbf{I}-\mathbf{A}_{\mathbf{N}}$, whose chemical stability lie in a close range $(\leq 1 \mathrm{kcal} / \mathrm{mol})$, and that the differences mainly concern the relative arrangement of the ester groups. In fact, there is a nice overlay between the crystallographic structure of compound Ia and the first conformation (population close to $56 \%$ ), as the differences in the orientation of the 
ester groups may arise from the replacement of the N-ethyl moiety (X-ray) by N-methyl (computational model) and the packing with other molecules in the X-ray structure (Figure 6).

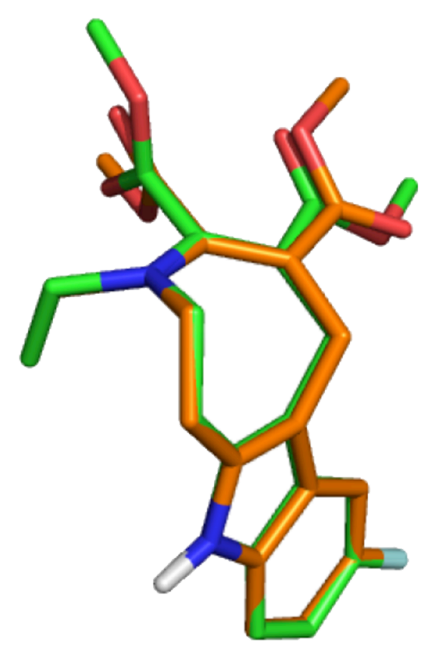

Figure 6. Superposition of the optimized structure of the neutral tautomer $\mathbf{I}-\mathbf{A}_{\mathbf{N}}$ (orange) determined from ML calculations and the crystallographic structure (green) for compound Ia (CCDC code: 218170).

With regard to the alternative tautomer $\mathbf{B}$, the protonated species $\mathbf{I}-\mathbf{B}_{\mathbf{P}}$ is found in three main conformational states (Supporting Information Figure S3). In contrast to the results obtained for $\mathbf{I}-\mathbf{A}_{\mathbf{P}}$, the shift of the double bond in the azocino moiety favors an extended arrangement of the fused indole-azocino rings, where the most stable conformation $\left(\mathbf{B}_{\mathbf{P}}{ }^{1}\right)$ has a population of $63.6 \%$ (Figure 5). Finally, the conformational space of tautomer $\mathbf{I}-\mathbf{B}_{\mathbf{N}}$ is represented by four major species (Supporting Information Figure S4), which reflect different arrangements of the ester substituents, albeit the main conformer contributes $62.2 \%$ of the conformational population (Figure 5).

Taking into account the conformational preferences of protonated and neutral species, the protonated tautomer $\mathbf{I}-\mathbf{B}_{\mathbf{P}}$ is favored by $15.4 \mathrm{kcal} / \mathrm{mol}$ compared to $\mathbf{I}-\mathbf{A}_{\mathbf{P}}$ (Figure 7), indicating that the population of $\mathbf{I}-\mathbf{A}_{\mathbf{P}}$ is negligible in aqueous solution, and that the protonated form can be represented by $\mathbf{I}-\mathbf{B}_{\mathbf{P}}$. The difference in stability between the two 
tautomers is much lower in the neutral state, and in fact the tautomer $\mathbf{I}-\mathbf{A}_{\mathbf{N}}$ is favored by almost $2 \mathrm{kcal} / \mathrm{mol}$. According to Figure 7, the $\mathrm{p} K_{\mathrm{a}}$ estimated for the deprotonation of the acidic species $\mathbf{I}-\mathbf{A}_{\mathbf{P}}\left(\mathrm{p} K_{\mathrm{a}}=-6.1\right)$ agrees with the value estimated using MarvinSketch ${ }^{\circledR}$ ( $\mathrm{p} K_{\mathrm{a}}$ of -5.7 for the enamino species of compound Ia in Table 2). Nevertheless, since protonation markedly favors the stability of tautomer $\mathbf{I}_{\mathbf{B}} \mathbf{B}_{\mathbf{P}}$, the titration of compound $\mathbf{I}$ can be described as the process that converts $\mathbf{I}-\mathbf{B}_{\mathbf{P}}$ into $\mathbf{I}-\mathbf{B}_{\mathbf{N}}$, leading to a predicted $\mathrm{p} K_{\mathrm{a}}$ of 6.4, which agrees with the experimental $\mathrm{p} K_{\mathrm{a}}$ determined for compound $\mathbf{I}\left(\mathrm{p} K_{\mathrm{a}}=6.1\right)$. Let us note, however, that the conversion between $\mathbf{I}-\mathbf{B}_{\mathbf{N}}$ and $\mathbf{I}-\mathbf{A}_{\mathbf{N}}$ should be kinetically impeded, because a fast conversion from $\mathbf{I}-\mathbf{B}_{\mathbf{N}}$ to $\mathbf{I}-\mathbf{A}_{\mathbf{N}}$, which is found to be the thermodynamically favored species, would lead to an estimated $\mathrm{p} K_{\mathrm{a}}$ of 5.2.

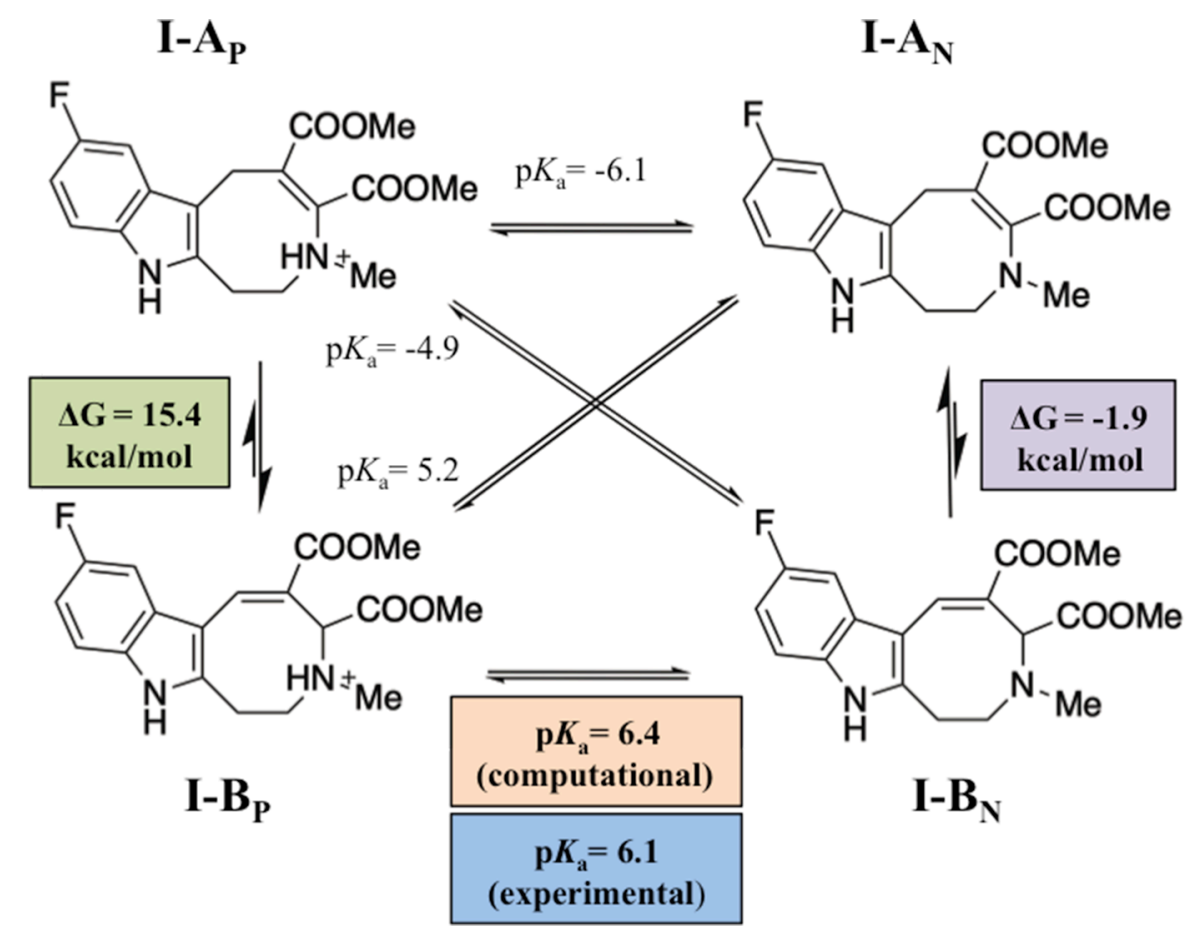

Figure 7. Relative stability of the different tautomeric species of compound $\mathbf{I}$ in aqueous solution and $\mathrm{p} K_{\mathrm{a}}$ values determined for the conversion between protonated and neutral species.

Multilevel analysis of compound II. The same methodological approach was used to explore the protonated and neutral species of compound II (Figure 8). The protonated species II-AP presents up to 8 distinct conformational states, including either structures 
where the azocino ring is folded toward the indole ring, reflecting the stabilization afforded by the positive charge of the protonated nitrogen with the $\pi$-electron density of the indole ring, or alternatively found in more extended arrangement. Indeed, the most populated folded and extended conformers account for almost 22\% $\left(\mathbf{A}_{\mathbf{P}}{ }^{1}\right)$ and $19 \%$ $\left(\mathbf{A}_{\mathbf{P}}{ }^{2}\right)$ of the conformational space (Figure 9; see also Supporting Information Figure S5). The flexibility of the azocine ring is also found in the neutral species, II-A $\mathbf{A}_{\mathbf{N}}$, which populates four major conformational states, the main species with a population close to 40\% (Figure 9 and Supporting Information Figure S6). It is worth noting that the skeleton of the most populated conformation superposes well the crystallographic structure of compound IIb (Figure 10).
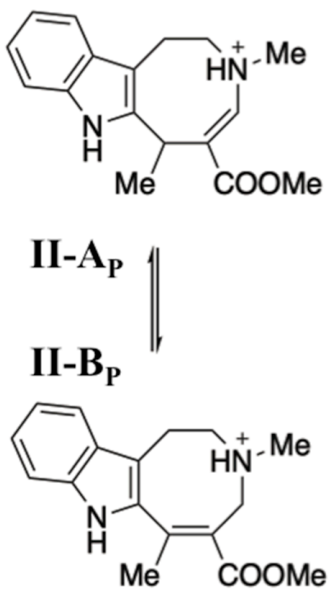
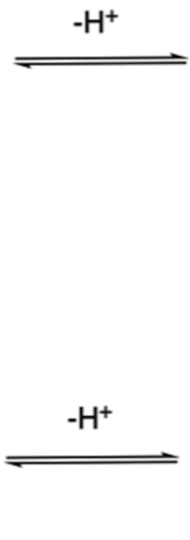<smiles>COC(=O)C1=CN(C)CCc2c([nH]c3ccccc23)C1C</smiles>

II-A

II-B $_{N}$

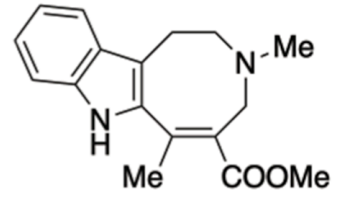

Figure 8. Representation of the ionization equilibria and tautomerism for protonated $\left(\mathbf{A}_{\mathbf{P}}, \mathbf{B}_{\mathbf{P}}\right)$ and neutral $\left(\mathbf{A}_{\mathbf{N}}, \mathbf{B}_{\mathrm{N}}\right)$ species of compound II. 


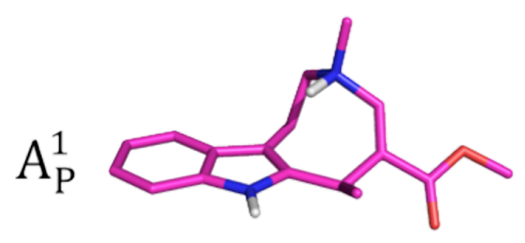

$(21.6 \%)$

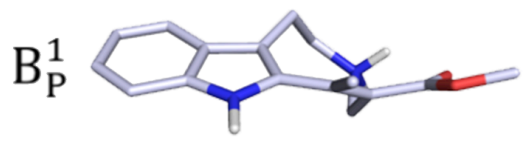

$(95.8 \%)$
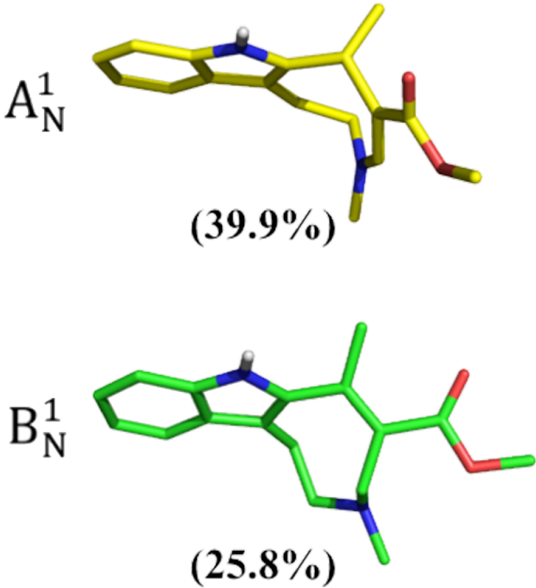

Figure 9. Main conformers in solution for the protonated $\left(\mathbf{A}_{\mathbf{P}}{ }^{1}, \mathbf{B}_{\mathbf{P}}{ }^{1}\right)$ and neutral $\left(\mathbf{A}_{\mathbf{N}}{ }^{1}, \mathbf{B}_{\mathbf{N}}{ }^{1}\right)$ tautomeric species of compound II determined from the Multilevel strategy. The population (\%) of the major symmetry-related conformation for each species is shown in parenthesis.

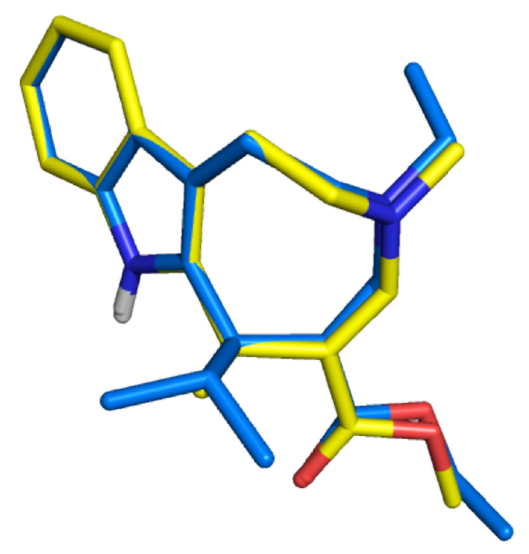

Figure 10. Superposition of the optimized structure of the neutral tautomer II-A $\mathbf{A}_{\mathbf{N}}$ (yellow) determined from ML calculations with the crystallographic structure (blue) for compound IIb (CCDC code: 229769).

In contrast to these results, the conformational distribution of the protonated species II$\mathbf{B}_{\mathbf{P}}$ is primarily reduced to a single conformational state, where the azocino ring adopts an extended arrangement stabilized by the intramolecular interaction between the protonated nitrogen and the carbonyl oxygen of the ester in position $\beta$ (population close to $96 \%$; Figure 9 and Supporting Information Figure S7). Finally, deprotonation increases the conformational flexibility of the neutral species II-B $\mathrm{B}_{\mathrm{N}}$, which can be found 
in four conformations that are similarly populated (Figure 9 and Supporting Information Figure S8).

By combining the relative stabilities of the conformations sampled for protonated species II-A $\mathbf{A}_{\mathbf{P}}$ and $\mathbf{I I}_{\mathbf{H}} \mathbf{B}_{\mathbf{P}}$, this latter tautomer is favored by $10.9 \mathrm{kcal} / \mathrm{mol}$, thus mimicking the behaviour found for compound I (see Figures 7 and 11). The analysis of the neutral forms reveals that $\mathbf{I I}-\mathbf{A}_{\mathbf{N}}$ was more stable than $\mathbf{I I}-\mathbf{B}_{\mathbf{N}}$ by $2.6 \mathrm{kcal} / \mathrm{mol}$ (Figure 11). If one assumes that deprotonation of II-B $\mathbf{P}$ leads to the thermodynamically favored species II-A $\mathbf{A}_{\mathbf{N}}$, the predicted $\mathrm{p} K_{\mathrm{a}}$ would be 6.8 , which is almost $2 \mathrm{p} K_{\mathrm{a}}$ units lower than the experimental value $\left(\mathrm{p} K_{\mathrm{a}}=8.8\right)$. In contrast, a nice agreement is found when the $\mathrm{p} K_{\mathrm{a}}$

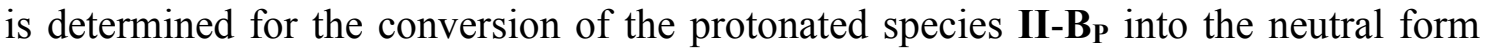
II-B $\mathbf{B}_{\mathbf{N}}$, as the predicted $\mathrm{p} K_{\mathrm{a}}$ amounts to 8.7 (Figure 11). This suggests that the conversion of the neutral tautomer $\mathbf{I I}-\mathbf{B}_{\mathbf{N}}$ into the thermodynamically more stable tautomeric form II-A $\mathbf{A}_{\mathbf{N}}$ should be kinetically impeded. In turn, this raises the questions about the most feasible mechanism involved in the prototropic tautomerism and the role of solvent molecules in assisting the proton transfer, which will be addressed in future studies. Finally, let us also remark that the predicted value for the conversion of the protonated species II-A $\mathbf{A}_{\mathbf{P}}$ to $\mathbf{I I}-\mathbf{A}_{\mathbf{N}}$ leads to a $\mathrm{p} K_{\mathrm{a}}$ value of -1.3 , which matches the empirical value provided by MarvinSketch ${ }^{\circledR}\left(\mathrm{p} K_{\mathrm{a}}\right.$ of -0.8 for the enamino species of compound IIc in Table 2). 


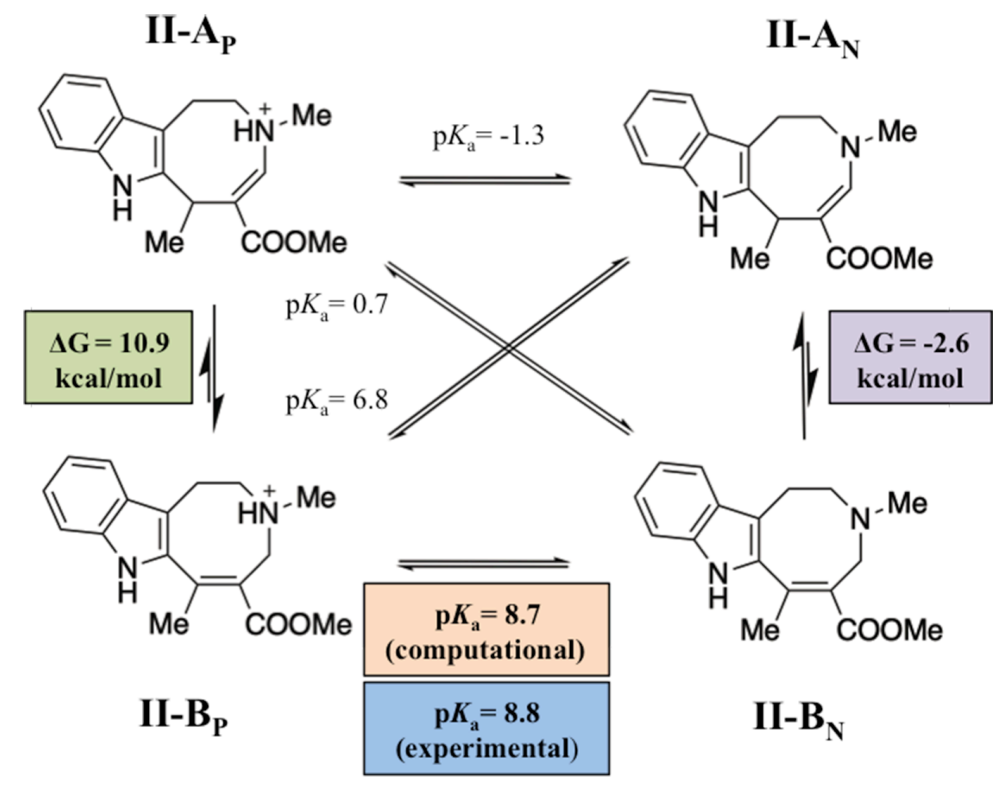

Figure 11. Relative stability of the different tautomeric species of compound $\mathbf{I I}$ in aqueous solution and $\mathrm{p} K_{\mathrm{a}}$ values determined for the conversion between protonated and neutral species.

\section{Effect of ester substituents on the tautomerism of protonated and neutral species.}

Comparison of the results shown in Figures 7 and 11 allow us to identify key factors that justify the differences in basicity of the two series of compounds represented by compounds I and II.

In the two protonated compounds there is a marked preference for the tautomeric species $\mathbf{B}_{\mathbf{P}}$, which is stabilized by more than $10 \mathrm{kcal} / \mathrm{mol}$ relative to tautomer $\mathbf{A}_{\mathbf{P}}$. Comparison of the hydration free energies of $\mathbf{A}_{\mathbf{P}}$ and $\mathbf{B}_{\mathbf{P}}$ reveals small differences $(<2$ $\mathrm{kcal} / \mathrm{mol}$ ), thus showing that the solvation of the positive charge has a minor effect in the relative stability between protonated tautomers. Therefore, the preference for $\mathbf{B}_{\mathbf{P}}$ can be attributed to the extended $\pi$-electron conjugation triggered upon shifting of the double bond between positions 4 and 5 in $\mathbf{A}_{\mathbf{P}}$ to positions 5 and 6 in $\mathbf{B}_{\mathbf{P}}$, enabling the conjugation with the electron density of the indole ring. In contrast the slight preference found for tautomer $\mathbf{A}_{\mathbf{N}}$ in the neutral species suggests a larger sensitivity to the specific pattern of the $\mathrm{COOR}_{3}$ group(s) in $\alpha$ and $\beta$ positions to nitrogen $\mathrm{N} 3$. 
To examine the influence of the ester groups, the relative stability of the two tautomers was determined for a simplified molecular system containing only the azocino ring with different ester substitutions, replacing the other chemical groups by hydrogen atoms (Supporting Information Table S1). For the model compound I, the presence of the ester group in position $\alpha$ or $\beta$ changes the relative stability from -3.9 to $+2.7 \mathrm{kcal} / \mathrm{mol}$, although there is a large cancellation of their influence when both esters are added simultaneously. For the model compound II, the tautomeric preference for the unsubstituted azocino ring is changed by $5.8 \mathrm{kcal} / \mathrm{mol}$ upon addition of the ester in position $\beta$, which tends to stabilize tautomer $\mathbf{A}_{\mathbf{N}}$. Overall, the results highlights the influence exerted by the electron-withdrawing ester groups on the tautomerism of tetrahydroazocino ester derivatives.

Effect of ester groups on the $\mathbf{p} \boldsymbol{K}_{\mathbf{a}}$. The preceding discussion points out that the experimental $\mathrm{p} K_{\mathrm{a}}$ describes the deprotonation of tautomers $\mathbf{I}-\mathbf{B}_{\mathbf{P}}$ and $\mathbf{I I}-\mathbf{B}_{\mathbf{P}}$ to $\mathbf{I}-\mathbf{B}_{\mathbf{N}}$ and II-B $\mathbf{B}_{\mathbf{N}}$, respectively (Scheme 2). This suggests that the carbomethoxy group in position $\beta$ exerts would increase the basicity of the nitrogen atom by ca. $2 \mathrm{p} K_{\mathrm{a}}$ units.

The preceding trends were further confirmed by experimental measurements of the $\mathrm{p} K_{\mathrm{a}}$ of two additional pairs of enamino ester-containing annulated medium-sized cyclic derivatives (Chart 1), namely $\beta-\mathrm{CO}_{2} \mathrm{Me}$ and $\alpha, \beta-\left(\mathrm{CO}_{2} \mathrm{Me}\right)_{2}$ derivatives of 4-ethyl1,4,5,6,7,8-hexahydroazonino[5,6-b]indole (IIIa-b) ${ }^{46,47}$ and 3-ethyl-1,2,3,6-tetrahydro8,9-dimethoxybenzo[d]azocine (IVa-b) ${ }^{48}$ The hexahydroazonino[5,6- $\left.b\right]$ indole scaffold III is a ring-expanded (azocine $\rightarrow$ azonine) analog of I, whereas the dimethoxybenzo moiety in IV replaces the indole ring in II. The $\mathrm{p} K_{\mathrm{a}}$ values were determined by potentiometric titration, but titrations were carried out in water-methanol mixtures due to the low water solubility of the examined compounds (Figure 12). The apparent $\mathrm{p} K_{\mathrm{a}}$ 
values enabled an accurate extrapolation to the $100 \%$ aqueous $\mathrm{p} K_{\mathrm{a}}$ (Table 4 ) according to Yasuda-Shedlovsky. ${ }^{37,38}$<smiles>COC(=O)C1=Cc2c([nH]c3ccc(F)cc23)CCN1C(=O)OC</smiles>

${\mathbf{I}-\mathbf{B}_{\mathrm{P}}}$<smiles>COC(=O)C1=C(C)CCN(C)CCc2c1[nH]c1ccccc21</smiles>

II-B $_{\mathbf{P}}$<smiles>COC(=O)C1=Cc2c([nH]c3ccc(F)cc23)CCN1C(C)=O</smiles>

$\mathbf{I}_{-} \mathbf{B}_{\mathrm{N}}$<smiles></smiles>

II-B $_{\mathbf{N}}$

Scheme 2. Representation of the deprotonation process for the ester derivatives of azocino compounds I and II.<smiles>[R]C1=C(C(C)=O)Cc2c([nH]c3ccc(C)cc23)CCCN1CC</smiles>

III-A<smiles>[R]C1=C(C(=O)OC)C(c2ccc(OC)cc2)c2cc(OC)c(OC)cc2CCN1CC</smiles>

IV-A $\mathbf{A}_{\mathbf{N}}$<smiles>[R2]C1/C(C(C)=O)=C/c2c([nH]c3ccc(C)cc23)CCCN1CC</smiles>

III-B $\mathbf{N}_{\mathbf{N}}$<smiles>[R2]C1C(C(=O)OC)=C(c2ccc(OC)cc2)c2cc(OC)c(OC)cc2CCN1CC</smiles>

IV-B $\mathbf{B}_{\mathbf{N}}$

Chart 1. Enamino (di)ester derivatives whose $\mathrm{p} K_{\mathrm{a}}$ values have been measured in this study to confirm theoretical predictions: (III) 1,4,5,6,7,8-hexahydroazonino[5,6-b]indole, and (IV) 1,2,3,6-tetrahydro-8,9-dimethoxybenzo[ $d]$ azocine. Diester $\left(\mathrm{R}_{2}=\mathrm{CO}_{2} \mathrm{Me}\right)$ and monoester $\left(\mathrm{R}_{2}=\right.$ $\mathrm{H})$ species are denoted $\mathbf{a}$ and $\mathbf{b}$ in the text. 

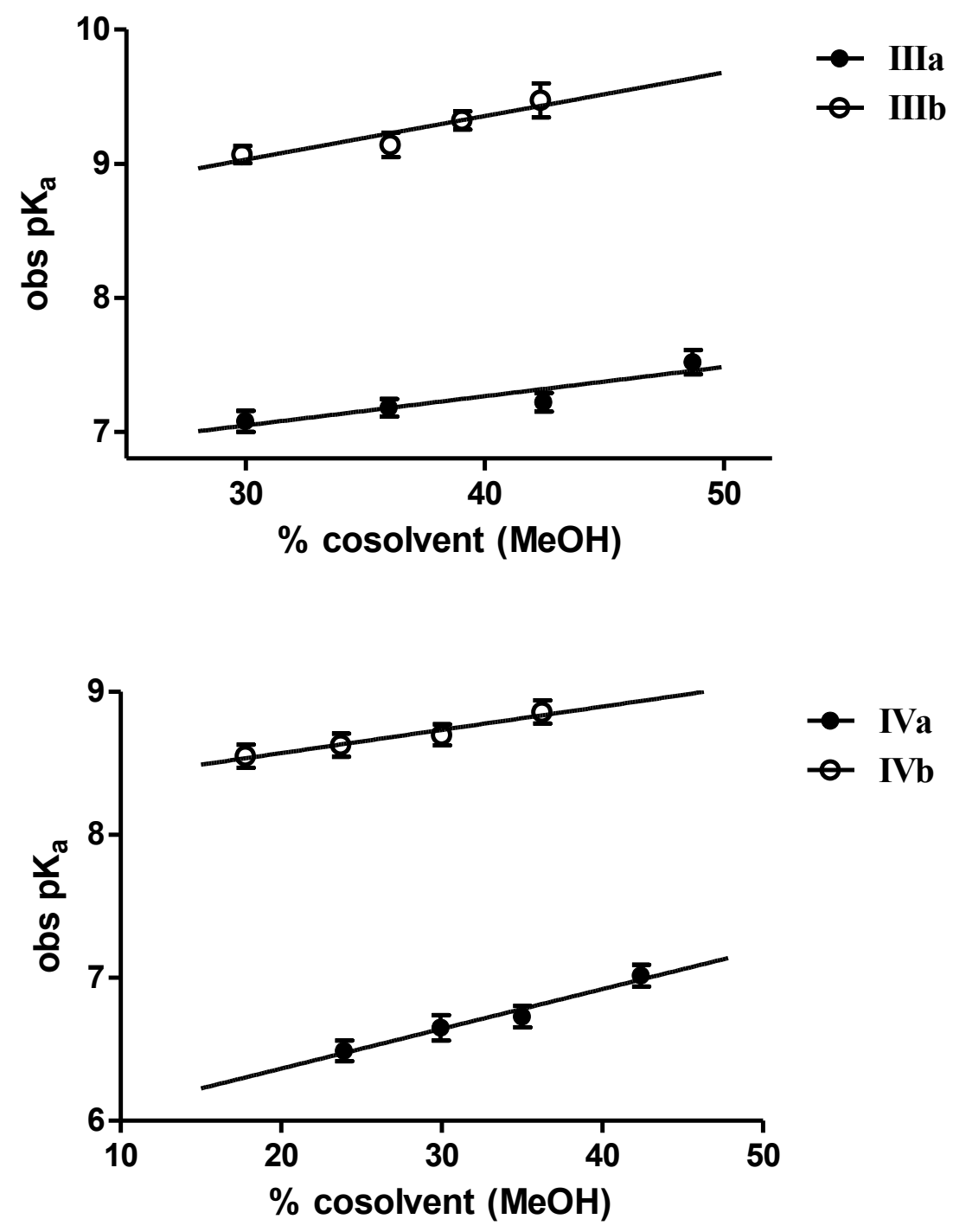

Figure 12. Dependence of $\mathrm{p} K_{\mathrm{a}}$ of cyclic enamino ester derivatives IIIa-b and IVa-b on the solvent composition (linear correlation $\mathrm{r}^{2} \geq 0.985$ ) determined in a mixture solution of methanol in $0.15 \mathrm{M} \mathrm{KCl}$ aqueous solution $(\% \mathrm{MeOH} v / \mathrm{v})$ at $25^{\circ} \mathrm{C}$.

Table 4. Experimental $\mathrm{p} K_{\mathrm{a}}$ Values (mean $\pm \mathrm{SD} ; \mathrm{n}=3$ ) for Representative Enamino (Di)ester Derivatives of Annelated Hexahydroazonino[5,6-b]indole (III), and Tetrahydro-8,9Dimethoxybenzo $[d]$ azocine (IV).

\begin{tabular}{|c|c|c|}
\hline Compound & $\mathbf{R}_{\mathbf{2}}$ & $\mathbf{E x p} \mathbf{p} \boldsymbol{K}_{\mathbf{a}}$ \\
\hline IIIa & COOMe & $6.50 \pm 0.10$ \\
\hline IIIb & $\mathrm{H}$ & $8.61 \pm 0.05$ \\
\hline IVa & COOMe & $6.01 \pm 0.03$ \\
\hline IVb & $\mathrm{H}$ & $8.30 \pm 0.04$ \\
\hline
\end{tabular}


The chemical changes introduced in compounds III and IV should have little effect on the preference for tautomer $\mathbf{B}_{\mathbf{P}}$, which indeed should be major species of the protonated compound according to the results of previous calculations for type I compounds (Figure 7). For the $\alpha, \beta$-diester derivative IIIa, the observed $\mathrm{p} K_{\mathrm{a}}$ is 6.5 , which is close to the values reported in Table 1 for both $\mathbf{I a}\left(\mathrm{p} K_{\mathrm{a}}=6.1\right)$ and $\mathbf{I b}\left(\mathrm{p} K_{\mathrm{a}}=6.7\right)$. The $\mathrm{p} K_{\mathrm{a}}$ of the diester compound IVa follows the same trend $\left(\mathrm{p} K_{\mathrm{a}}=6.0\right)$. On the other hand, the absence of the $\alpha$-carbomethoxy group does increase the basicity of the enamino group by more than $2 \mathrm{p} K_{\mathrm{a}}$ units: from 6.5 (IIIa) to 8.6 (IIIb) and from 6.0 (IVa) to 8.3 (IVb), following the behavior observed for Ic $\left(\mathrm{p} K_{\mathrm{a}}=8.2\right)$. These results can be understood if one assumes that the measured $\mathrm{p} K_{\mathrm{a}}$ corresponds to the deprotonation of the tautomeric species $\mathbf{B}_{\mathbf{P}}$.

\section{CONCLUSIONS}

The analysis of the results presented in this work points out that the presence of tautomeric forms that convert the enamine species into a secondary amine has a key influence on the experimental $\mathrm{p} K_{\mathrm{a}}$ of the ester derivatives of annulated tetrahydroazocino (and hexahydroazonino as well) compounds. The results reveal that the tautomeric form $\mathbf{B}$ is predicted to be the most stable species for the protonated form in the two representative compounds considered in our study. Therefore, rather than the enamine species, titration of these azocino-based compounds reflects the deprotonation of a secondary amine, even though the experimental $\mathrm{p} K_{\mathrm{a}}$ also reflects the synergy between different factors, such as the pattern of ester substituents attached to the azocino ring. 
If one assumes that deprotonation is controlled by thermodynamic stability, the predicted $\mathrm{p} K_{\mathrm{a}}$ for compounds I and II would underestimate the experimental value by 1$2 \mathrm{p} K_{\mathrm{a}}$ units. In contrast, deprotonation of the tautomeric species $\mathbf{B}\left(\mathbf{I}-\mathbf{B}_{\mathbf{P}}\right.$ and $\left.\mathbf{I I}-\mathbf{B}_{\mathbf{P}}\right)$

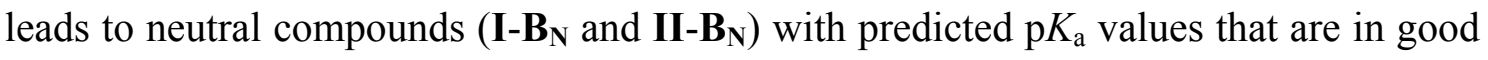
agreement with the experimental values, as noted in the comparison of the predicted values of 6.4 and 8.7 with the corresponding experimental ones, which are 6.1 and 8.8 , respectively. This suggests that the conversion of neutral species $\mathbf{I}-\mathbf{B}_{\mathbf{N}}$ and $\mathbf{I I}-\mathbf{B}_{\mathbf{N}}$ to the thermodynamically more favored $\mathbf{I}-\mathbf{A}_{\mathbf{N}}$ and $\mathbf{I I}-\mathbf{A}_{\mathbf{N}}$ is kinetically impeded.

Keeping in mind that tautomer $\mathbf{B}$ represents the protonated form of these compounds, this study provides a basis to rationalize the differential effects of the two ester groups on the modulation of the $\mathrm{p} K_{\mathrm{a}}$. Thus, whereas a stabilization of the $\pi$-electron delocalization with the indole ring can be expected from the ester group in position $\beta$, the ester group in position $\alpha$ exerts an inductive effect that decreases the basicity of the azocino nitrogen by almost $2 \mathrm{p} K_{\mathrm{a}}$ units. Accordingly, the apparently minor chemical modification arising upon deletion of this ester group may have a drastic impact on the nature of the most populated species at physiological $\mathrm{pH}$, affecting the pharmacodynamics and pharmacokinetics profiles of these compounds.

Finally, this study exemplifies the suitability of the Multilevel strategy to take into account the influence exerted by the substituents on the interplay between ionization, tautomerism, and conformational flexibility, which enables a subtle regulation of the bioactive species. This approach can then be valuable to explore the relationships between biological activity and the bioactive species of drug-like compounds at two levels. First, exploring the complementarity between the chemical groups present in a specific compound, which depend on the ionization, tautomerism and conformational preferences, and the $3 \mathrm{D}$ arrangement of residues in the binding pocket of the target. 
Second, the prediction of properties such as solubility and distribution, which are useful to estimate a priori the suitability of the pharmacokinetics profile of the compound.

\section{ASSOCIATED CONTENT}

\section{(S) Supporting Information}

The Supporting Information is available free of charge on the ACS Publications website at DOI:

- Figures S1-S8 with conformational preferences of the tautomers of compounds I and II

- Table S1 with the relative energies of tautomers for simplified models of of the 1,2,3,6-tetrahydroazocino moiety.

- Optimized structures and energies of the tautomers of compound I and II

\section{AUTHOR INFORMATION}

\section{Corresponding Author}

*E-mail: fjluque@ub.edu.

\section{ORCID}

Antonio Viayna: 0000-0002-2112-5828

Salvatore G. Antermite: 0000-0001-5874-481X

Modesto de Candia: 0000-0002-4570-1981

Cosimo D. Altomare: 0000-0001-5016-5805

F. Javier Luque: 0000-0002-8049-3567

\section{Notes}

The authors declare no competing financial interest. 


\section{ACKNOWLEDGEMENTS}

This work was supported by the Spanish Ministerio de Economia y Competitividad (MINECO, SAF2017-88107-R; AEI/FEDER UE), the Generalitat de Catalunya (2017SGR1746) for financial support, and the Consorci de Serveis Universitaris de Catalunya (CSUC, Molecular Recognition project) for computational facilities. A. V. is a fellow from the Universitat de Barcelona. M.d.C. and C.D.A. gratefully acknowledge the kind gift of samples of compounds IIIa-b and IVa-b by Prof. Leonid G. Voskressensky, Department of Organic Chemistry of the Peoples Friendship University of Russia (RUDN University, Moscow, Russian Federation). 


\section{REFERENCES}

(1) Golhke, H.; Klebe, G. Approaches to the Description and Prediction of the Binding Affinity of Small-Molecule Ligands to Macromolecular Receptors. Angew. Chem. Int. Ed. 2002, 41, 2644-2676.

(2) Altomare, C.; Cellamare, S.; Summo, L.; Fossa, P.; Mosti, L.; Carotti, A. Ionization Behaviour and Tautomerism-Dependent Lipophilicity of Pyridine-2(1H)-one Cardiotonic Agents. Bioorg. Med. Chem. 2000, 8, 909-916.

(3) De Candia, M.; Fossa, P.; Cellamare, S.; Mosti, L.; Carotti, A.; Altomare, C. Insights into Structure-Activity relationships from Lipophilicity Profiles of Pyridin2(1H)-one Analogs of the Cardiotonic Agent Milrinone. Eur. J. Pharm. Sci. 2005, 26, $78-86$.

(4) Manallack, D. T. The $\mathrm{p} K_{\mathrm{a}}$ Distribution of Drugs: Application to Drug Discovery. Perspect. Medicin. Chem. 2007, 1, 25-38.

(5) Martin, Y. C. Let's Not Forget Tautomers. J. Comput. Aided Mol. Des. 2009, 23, $693-704$.

(6) Onufriev, A. V.; Alexov, E. Protonation and $\mathrm{p} K$ Changes in Protein-Ligand Binding. Q. Rev. Biophys. 2013, 46, 181-209.

(7) Haworth, N. L.; Wang, Q.; Coote, M. L. Modeling Flexible Molecules in Solution: A pKa Case Study. J. Phys. Chem A. 2017, 121, 5217-5225.

(8) Phillip, D. M.; Watson, M. A.; Yu, H. S.; Steinbrecher, T. B.; Bochevarov, A. D. Quantum Chemical $\mathrm{p} K_{\mathrm{a}}$ Prediction for Complex Organic Molecules. Int. J. Quantum Chem. 2018, 118, e25561.

(9) Martin, Y. C. Experimental and $\mathrm{p} K_{\mathrm{a}}$ Prediction Aspects of Tautomerism of DrugLike Molecules. Drug Discov. Today Technol. 2018, 27, 59-64. 
(10) Hudáky, P.; Perczel, A. Conformation Dependence of pKa: Ab Initio and DFT Investigation of Histidine. J. Phys. Chem. A 2004, 108, 6195-6205.

(11) Forti, F.; Cavasotto, C.; Orozco, M.; Barril, X.; Luque, F. J. A Multilevel Strategy for the Exploration of the Conformational Flexibility of Small Molecules. J. Chem. Theory Comput. 2012, 8, 1808-1819.

(12) Olsen, J. I.; Sauer, S. P. A.; Pedersen, C. M.; Bols, M. Exploring the Relationship Between the Conformation and $\mathrm{pKa}$ : Can a $\mathrm{pKa}$ value be used to Determined the Conformational Equilibrium? Org. Biomol. Chem. 2015, 13, 3116-3121.

(13) Juárez-Jiménez, J.; Barril, X.; Orozco, M.; Pouplana, R.; Luque, F. J. Assessing the Suitability of the Multilevel Strategy for the Conformational Analysis of Small Ligands. J. Phys. Chem. B. 2015, 119, 1164-1172.

(14) Avdeef, A. Physicochemical Profiling (Solubility, Permeability and Charge State). Curr. Top. Med. Chem. 2001, 1, 277-351.

(15) Remko, M.; Remkóva, A.; Broer, R. A Comparative Study of Molecular Structure, pKa, Lipophilicity, Solubility, Absorption and Polar Surface Area of Some Antiplatelet Drugs. Int. J. Mol. Sci. 2016, 17, 388.

(16) Voskressensky, L. G.; Borisova, T. N.; Kulikova, L. N.; Varlamov, A. V.; Catto, M.; Altomare, C.; Carotti, A. Tandem Cleavage of Hydrogenated $\beta$ - and $\gamma$-Carbolines New Practical Synthesis of tetrahydroazocino[4,5- $b$ ]indoles and Tetrahydroazocino[5,4b]indoles Showing Acetylcholinesterase Inhibitory Activity. Eur. J. Org. Chem. 2004, $14,3128-3135$.

(17) Carotti, A.; de Candia, M.; Catto, M.; Borisova, T. N.; Varlamov, A. V.; MéndezÁlvarez, E.; Soto-Otero, R.; Voskressensky, L. G.; Altomare, C. Ester Derivatives of Annulated Tetrahydroazocines: A New Class of Selective Acetylcholinesterase Inhibitors. Bioorg. Med. Chem. 2006, 14, 7205-7212. 
(18) Groom, C. R. Bruno, I. J. Lightfoot, M. P.; Ward, S. C. The Cambridge Structural Database. Acta Crystallogr. B. 2016, B72, 171-179.

(19) Kelly, C. P.; Cramer, C. J. Truhlar, D. G. Aqueous Solvation Free Energies of Ions and Ion Water Clusters Based on an Accurate Value for the Absolute Aqueous Solvation Free Energy of the Proton. J. Phys. Chem. B. 2006, 110, 16066-16081.

(20) McQuarrie, D. M. Statistical Mechanics; Harper and Row: New York, 1970, p 86.

(21) Hanwell, M. D.; Curtis, D. E.; Lonie, D. C.; Vandermeersch, T.; Zurek, E.; Hutchison, G. R. Avogadro: An Advanced Semantic Chemical Editor, Visualization, and Analysis Platform. J. Cheminformatics. 2012, 4, 17.

(22) Case, D. A.; Betz, R. M.; Cerutti, D. S.; Cheatham, T. E. I. I. I.; Darden, T. A.; Duke, R. E.; Giese, T. J.; Gohlke, H.; Goetz, A. W. Homeyer, N. et al. AMBER 2016; University of California, San Francisco, CA, 2016.

(23) Frisch, M. J.; Trucks, G. W.; Schlegel, H. B.; Scuseria, G. E.; Robb, M. A.; Cheeseman, J. R.; Scalmani, G.; Barone, V.; Petersson, G. A.; Nakatsuji, H. et al. Gaussian 16, revision B.01; Gaussian, Inc.; Wallingford, CT, 2016.

(24) Head, M. S.; Given, J. A.; Gilson, M. K. Mining Minima: Direct Computation of Conformational Free Energy. J. Phys. Chem. A 1997, 101, 1609-1618.

(25) Chen, W.; Chang, C.; Gilson, M. K. Calculation of Cyclodextrin Binding Affinities: Energy, Entropy, and Implications for Drug Design. Biophys. J. 2004, 87, 3035-3049.

(26) Jorgensen, W. L.; Chandrasekhar, J.; Madura, J. D.; Impey, R. W.; Klein, M. L. Comparison of Simple Potential Functions for Simulating Liquid Water. J. Chem. Phys. 1983, 79, 926-935.

(27) Wang, J.; Wolf, R. M.; Caldwell, J. W.; Kollman, P. A.; Case, D. A. Development and Testing of a General Amber Force Field. J. Comput. Chem. 2004, 25, 1157-1174. 
(28) Bayly, C. I.; Cieplak, P.; Cornell, W.; Kollman, P. A. A Well- Behaved Electrostatic Potential Based Method Using Charge Restraints for Deriving Atomic Charges: The RESP Model. J. Phys. Chem. 1993, 97, 10269-10280.

(29) Ryckaert, J.-P.; Ciccotti, G.; Berendsen, H. J. C. Numerical Integration of the Cartesian Equations of Motion of a System with Constraints: Molecular Dynamics of nAlkanes. J. Comput. Phys. 1977, 23, 327-341.

(30) Darden, T.; York, D.; Pedersen, L. Particle Mesh Ewald: An Nlog(N) Method for Ewald Sums in Large Systems. J. Chem. Phys. 1993, 98, 10089-10092.

(31) Curutchet, C.; Bidon-Chanal, A.; Soteras, I.; Orozco, M.; Luque, F. J. MST Continuum Study of the Hydration Free Energies of Monovalent Ionic Species. J. Phys. Chem. B 2005, 109, 3565-3574.

(32) Soteras, I.; Curutchet, C.; Bidon-Chanal, A.; Orozco, M.; Luque, F. J. Extension of the MST Model to the IEF Formalism: HF and B3LYP Parametrizations. J. Mol. Struct.: THEOCHEM 2005, 727, 29-40.

(33) Avdeef, A.; Box, K. J.; Comer, J. E. A.; Hibbert, C.; Tam, K. Y. pH-Metric logP 10. Determination of Liposomal Membrane-Water Partition Coefficients of Ionizable Drugs. Pharm. Res. 1998, 15, 209-215.

(34) Avdeef, A. pH-Metric log P. II: Refinement of Partition Coefficients and Ionization Constants of Multiprotic Substances. J. Pharm. Sci. 1993, 82, 183-190.

(35) De Candia, M.; Altamura, C.; Denora, N.; Cellamare, S.; Nuzzolese, M.; De Vito, D.; Voskressensky, L. G.; Varlamov, A. V.; Altomare, C. D. Physicochemical Properties and Antimicrobial Activity of New Spirocyclic Thieno[2,3-d]pyrimidin4(3H)-one Derivatives. Chem Heterocycl. Compd. 2017, 53, 357-363. 
(36) Avdeef, A.; Comer, J. E. A.; Thomson, S.J. pH-Metric log P.3. Glass Electrode Calibration in Methanol-Water, Applied to $\mathrm{p} K_{\mathrm{a}}$ Determination of Water-Insoluble Substances. Anal. Chem. 1993, 65, 42-49.

(37) Yasuda, M. Dissociation constants of some carboxylic acids in mixed aqueous solvents. Bull. Chem. Soc. Jpn. 1959, 32, 429-432.

(38) Shedlovsky, T. In Electrolytes; Pesce, B., Ed.; Pergamon, New York, 1962, pp. $146-151$.

(39) Avdeef, A.; Box, K. J.; Comer, J. E. A.; Gilges, M.: Hadley, M.; Hibbert, C.; Patterson, W.; Tam, K. Y. $\mathrm{pK}_{\mathrm{a}}$ Determination of Water-Insoluble Drugs in Organic Solvent-Water Mixtures. J. Pharm. Biomed. Anal. 1999, 20, 631-641.

(40) MarvinSketch, version 17.29.0; ChemAxon Ltd.: Budapest, Hungary 2017

(41) ACD/Labs, version 2014.1; Advanced Chemistry Development, Inc.: Toronto, ON 2014.

(42) Liao, C.; Nicklaus, M. C. Comparison of Nine Programs Predicting $\mathrm{pK}_{\mathrm{a}}$ Values of Pharmaceutical Substances. J. Chem. Inf. Model. 2009, 49, 2801-2812.

(43) Ribeiro, A. R.; Schmidt, T. C. Determination of Acid Dissociation Constants $\left(\mathrm{pK}_{\mathrm{a}}\right)$ of Cephalosporin Antibiotics: Computational and Experimental Approaches. Chemosphere 2017, 169, 524-533.

(44) Toure, O.; Dussap, C.-G.; Lebert, A. Comparison of Predicted $\mathrm{pK}_{\mathrm{a}}$ Values for Some Amino-Acids, Dipeptides and Tripeptides, Using COSMO-RS, ChemAxon and ACD/LABS Methods. Oil Gas. Sci. Technol. Rev. IFP Energies Nouv. 2013, 68, $281-297$.

(45) Settimo, L.; Bellman, K.; Knegtel, R. M. A. Comparison of the Accuracy of Experimental and Predicted $\mathrm{pK}_{\mathrm{a}}$ Values of Basic and Acidic Compounds. Pharm. Res. 2014, 31, 1082-1095. 
(46) Voskressensky, L. G.; Listratova, A. V.; Borisova, T. N.; Alexandrov, G. G.; Varlamov, A. V. Synthesis of Benzoazocines from Substituted Tetrahydroisoquinolines and Activated Alkynes in a Tetrahydropyridine Ring Expansion. Eur. J. Org. Chem. 2007, 36, 6106-8117.

(47) Voskressensky, L. G.; Borisova, T. N.; Listratova, A. V.; Kulikova, L. N.; Titov, A. A.; Varlamov, A. V. Tandem Enlargement of The Tetrahydropyridine Ring in 1Aryl-Tetrahydroisoquinolines Using Activated Alkynes - A New and Effective Synthesis of Benzoazocines. Tetrahedron Lett. 2006, 47, 4585-4589.

(48) Voskressensky, L. G.; Akbulatov, S. V.; Borisova, T. N.; Varlamov, A. V. A Novel Synthesis of Hexahydroazoninoindoles Using Activated Alkynes in an Azepine Ring Expansion. Tetrahedron 2006, 62, 12392-12397. 